\title{
A study of volatility behaviour of S\&P BSE BANKEX return in India: A pragmatic approach using GARCH model
}

\author{
Azeem Ahmad Khan ${ }^{1, *}$, Sarfaraz Javed ${ }^{2}$ \\ ${ }^{1}$ Department of Commerce, Gagan College of Management \& technology, Aligarh, UP, India \\ ${ }^{2}$ Department of Management, JIT, Lucknow, UP, India
}

\section{A R T I C L E I N F O}

\section{Article history:}

Received 22 December 2016

Received in revised form

25 February 2017

Accepted 29 February 2017

\section{Keywords:}

Garch

Bankex

Sensex
NASDAQ

Volatility

\begin{abstract}
A B S T R A C T
The purpose of this study is to know that how the National and International market, namely (S\&P BSE SENSEX) (NASDAQ) (SSE) (FTSE) can influence the volatility of (S\&P BSE BANKEX) return in India and the factors affecting the volatility for the same. However, the previous studies mostly considered the volatility of stock in the Indian capital market. But the present study mainly focuses on the Bankex return volatility. Here the researcher identified and estimated the mean and variance components of the daily Bankex return using Garch $(1,1)$ model by explaining the volatility structure of the residuals obtained under the best-suited model for the used data series. The method ML - ARCH (Marquardt) - Normal distribution has satisfied the criterion of model selection based on the three assumptions. These Null Hypotheses deals with the problems firstly, no serial correlation, secondly, the presence of no ARCH effect, thirdly, residual are normally distributed. We have chosen daily data period from 03rd May, 2012 to 08th January 2016, nearly 914 working days of all markets for estimating Arch-Garch model. The study shows the significant result of ARCH and GARCH effect. The Bankex Return is also significantly affected by endogenous variable (SENSEX return). The NASDAQ composite and SSE composite Index are also statistically significant, In sum-up, the foreign market return volatility or outside shock can influence the volatility of BANKEX return. However, the FTSE 100 was not found statistically significant, revealing that volatility in FTSE return cannot transmit to S\&P BSE BANKEX return in India.
\end{abstract}

(C) 2017 The Authors. Published by IASE. This is an open access article under the CC BY-NC-ND license (http://creativecommons.org/licenses/by-nc-nd/4.0/).

\section{Introduction}

Estimation of the volatility pattern of S\&P BSE Bankex index of India is significant in relation to various applications of the financial market, India is one of the fastest growing country in the world and this reflected by emerging capital market. In financial economics, volatility clustering refers to the observation as noted by Mandelbrot (1963) which showed that, large changes tend to be followed by large changes of either sign and small changes tend to be followed by small changes. In the past, traditional models were used to test the volatility variance, stock market volatility and estimation of the market and to have established great importance not only to the investors but also to financial practitioners and academicians, especially in the

\footnotetext{
* Corresponding Author.

Email Address: aakcommerce@gmail.com (A. A. Khan) https://doi.org/10.21833/ijaas.2017.04.018

2313-626X/C 2017 The Authors. Published by IASE.

This is an open access article under the CC BY-NC-ND license

(http://creativecommons.org/licenses/by-nc-nd/4.0/)
}

area of security analysis and portfolio management. Financial modeling highlights the facts that the stock price or market movement exhibits certain major formalized facts such as volatility clustering, conditional Heteroscedasticity, asymmetric volatility effect, unconditional time-varying movement. The arch model commonly used in financial modeling of time series data that exhibits time varying volatility clustering. i.e., periods of swings interspersed with a period of relative calm. The news impact bends to measure how new information is incorporated into volatility estimates. A variety of new and existing ARCH models are compared and estimated with daily Japanese stock return data to determine the shape of the News Impact Curve. New diagnostic tests are presented which emphasize the asymmetry of the volatility response to the news. An Arch model can estimate using Least Squares Method. Estimation of volatility is an interest of expert and researcher, the autoregressive conditional Heteroscedasticity (Arch model) introduced by Engle (1982) and later generalized by Bollerslev (1986) after numerous studies have been done on modeling volatility in the 
different market. Empirically, the family of a Garch model has been successful in describing the financial data, out of this group of a model, the Garch $(1,1)$ is often recognized or considered by most appropriate to be an excellent model for estimating conditional volatility for a wide range of financial data. In this study, the S\&P BSE Bankex includes all major banks in India. A pragmatic approach using Garch $(1,1)$ model has been applied to test the volatility in return, by using residual or error term, also the estimation of volatility is made at the macro level on four major indices around the world, namely S\&P BSE SENSEX, NASDAQ composite, SSE composite Index, FTSE100. The fitted model is then evaluated in term of its forecasting accuracy on these four indices.

\section{Literature review}

After gone through available literature review, a number of studies have been conducted on the volatility of Indian capital market. According to these studies, it is hard to obtain a definite conclusion that the Indian capital market is volatile or not. In the beginning; French et al. (1987) studied the expected stock returns and volatility and Schwert (1989) determined why stock market volatility changes over time, followed by Engle and Ng (1993) they measured and tested the impact of news on volatility, while Aggarwal et al. (1999) tested the kinds of events that cause large shifts in the volatility of emerging stock markets. Kaur (2004) explored the nature and characteristics of stock market volatility in India that exhibits characteristics similar to those who found earlier in many of the major developed and emerging stock markets. Various volatility estimates and diagnostic tests indicated volatility clustering, i.e., shocks to the volatility process persist and the response to news arrival was asymmetrical, meaning that the impact of good and bad news is not the same. Kulkarni and Deo (2005) observed the volatility of an Indian stock market in terms of aspects like participation, synchronization of stocks and quantification of volatility using the random matrix approach. Pandey (2005) compared the empirical performance of various unconditional volatility estimators and conditional volatility models (GARCH and EGARCH) using time-series data of S\&PCNX Nifty, a value-weighted index of 50 stocks traded on the National Stock Exchange (NSE), Mumbai Estimates computed by various estimators and conditional volatility models over non overlapping one-day, five-day and one-month periods are compared with the "Realized Volatility" measured over the same period. Karmakar (2005) tried to estimate conditional volatility models to capture the salient features of stock market volatility in India and evaluated the models in terms of out of sample forecast accuracy and also investigated whether there is any leverage effect on Indian companies. The estimation of volatility was made at the macro level on two major market indices, namely, S\&P CNX Nifty and BSE Sensex. Alberg et al.
(2008) made an earnest attempt at empirical analysis of the mean return and the conditional variance of Tel Aviv Stock Exchange (TASE) where indices were performed using various GARCH models. Their results showed that the asymmetric GARCH model with fat-tailed densities improves overall estimation for measuring conditional variance. The E-GARCH model used a skewed student-t distribution which is the most successful tool for forecasting TASE indices. Joshi (2010) investigated that the stock market volatility in the emerging stock markets of India and China uses the daily closing price from 1st January, 2005 to 12 th May, 2009. The results mark the presence of nonlinearity through BDSL test while conditional heteroskedasticity was identified through ARCH-LM test. It was found that the GARCH $(1,1)$ model successfully captures nonlinearity and volatility clustering. The results of the study suggested that the persistence of volatility in Chinese stock market is more than Indian stock market. Goudarzi and Ramanarayanan (2011) empirically tested the effects of good and bad news on volatility in the Indian stock markets using asymmetric ARCH models during the global financial crisis of 2008-09. The presence of the leverage effect would imply that the negative innovation (news) has a greater impact on volatility than positive innovation news. It concluded that, the bad news in the Indian stock market increases volatility more than the good news. Chand et al. (2012) examined the modelling and volatility analysis of share prices using ARCH and GARCH models. Trivedi (2013) examined the Performance Analysis of Bankex Banks through Camel Model, Prasanna and Menon (2013) examined the speed at which information gets incorporated into the various stock indices in India. They took four alternate speed estimators viz., the AR (1) model, the ARMA $(1,1)$ model, the ARMA $(1, X)$ model, and the cross-covariance estimator was calculated to estimate the rate at which information is adjusted. Birău et al. (2015) empirically tested the volatility patterns of the S\&P Bombay Stock Exchange (BSE) BANKEX index which is the Indian banking sector index. Currently, the Indian banking sector is one of the fastest growing sectors and all major banks have been included in the S\&P BANKEX index. The financial econometric approach includes GARCH (1, 1) model which is performed in order to capture asymmetric volatility clustering and leptokurtosis. The volatility impact has generated highly positive clockwise and resulted in actual stocks. The results revealed that the BANKEX index grown over 17 times in 12 years and volatility returns have been found present in the listed stocks.

\section{Objectives of the study}

- To study the existence of the volatility of the (S\&P BSE BANKEX) return in India.

- To trace the factors affecting the volatility of (S\&P BSE BANKEX) return in India. 


\section{Hypotheses of the study}

H01: Null Hypothesis assumes that there is no volatility of the (S\&P BSE BANKEX) Return.

H02: Null Hypothesis assumes that there is no impact of the National market (S\&P BSE SENSEX) return on (S\&P BSE BANKEX) Return.

H03: Null Hypothesis assumes that there is no impact of International market (NASDAQ, SSE and FTSE return on S\&P BSE BANKEX) Return.

\section{Data collection and methodology}

The data used in this paper has been collected from the reliable source. The historical daily data of S\&P BSE SENSEX and S\&P BSE BANKEX is collected from Bombay Stock Exchange and the daily data of the NASDAQ (American stock exchange) SSE composite index (China) and FTSE100 index (UK) from $03^{\text {rd }}$ May, 2012 to $08^{\text {th }}$ Jan, 2016 nearly 914 working days of all markets. The market return of different indices is calculated using the formulae:

$\mathrm{R}_{m}=\frac{\text { (CurrentDayClosePrice }- \text { PreviousDayClosePrice) }}{\text { PreviousDayClosePrice }} \times 100$
Historically, the stationary of data is usually derived from time plots and correlogram. The unit root test determines whether a time series is stationary or not. While using Dickey fuller test there may create a problem of autocorrelation. To deal with this problem, the researcher applied ADF test to the original series of (S\&P BSE SENSEX) (NASDAQ) (SSE) (FTSE) and (S\&P BSE BANKEX) and found unit root or non-stationary at level, therefore researcher again applied ADF test on first order differenced series, the results found that the series are stationary which satisfied all test Eqs. 1, 2, and 3, this is shown in Table 1. However, the researcher used PP- test in support of ADF test.

After the use of pp-test for examining the existence of unit root, the pp-test verifies the result of ADF test. In this test the series is found to be stationary at first differences. The pp-test does not assume residual, the researcher believes that there is a need to conduct both test ADF test and PP-test as well to find the robust conclusion (Table 2).

$\Delta \mathrm{Yt}=\mathrm{B} 1+\mathrm{ZYt}-1+\mathrm{ai}+\mathrm{et}(\mathrm{Eq} .1)>$ Intercept Only $\Delta \mathrm{Yt}=\mathrm{B} 1+\mathrm{B} 2 \mathrm{t}+\mathrm{ZYt}-1+\mathrm{ai}+\mathrm{et}$ (Eq. 2) $>$ Trend and Intercept $\Delta \mathrm{Yt}=\mathrm{ZYt}-1+\mathrm{ai}+\mathrm{et}$ (Eq. 3) $>$ No Trend, No Intercept

Table 1: The result of Augmented Dickey-Fuller (ADF) for first order differenced series of S\&P BSE Bankex, S\&P BSE SENSEX, NASDAQ, SSE Composite Index and FTSE 100 market return

\begin{tabular}{|c|c|c|c|c|c|c|}
\hline & Exogenous & Variable & Coefficient & Std. Error & t-Statistic & Prob. \\
\hline & Constant & D(BANKEX(-1)) & -5.682453 & 0.350751 & -16.20082 & 0.0000 \\
\hline \multirow[t]{3}{*}{ (S\&P BSE BANKEX) } & Constant, Linear Trend & D(BANKEX $(-1))$ & -5.684841 & 0.351009 & -16.19572 & 0.0000 \\
\hline & None & D(BANKEX $(-1))$ & -5.682431 & 0.350551 & -16.21002 & 0.0000 \\
\hline & Constant & D(SENSEX(-1)) & -4.839496 & 0.262339 & -18.44750 & 0.0000 \\
\hline \multirow[t]{3}{*}{ (S\&P BSE SENSEX) } & Constant, Linear Trend & D(SENSEX(-1)) & -4.841270 & 0.262532 & -18.44069 & 0.0000 \\
\hline & None & D(SENSEX(-1)) & -4.839519 & 0.262192 & -18.45793 & 0.0000 \\
\hline & Constant & D(NASDAQ $(-1))$ & -6.640484 & 0.417759 & -15.89547 & 0.0000 \\
\hline \multirow[t]{3}{*}{ (NASDAQ) } & Constant, Linear Trend & D(NASDAQ $(-1))$ & -6.644224 & 0.418029 & -15.89419 & 0.0000 \\
\hline & None & D(NASDAQ $(-1))$ & -6.640150 & 0.417534 & -15.90325 & 0.0000 \\
\hline & Constant & $\mathrm{D}(\operatorname{SSE}(-1))$ & -4.617468 & 0.218839 & -21.09988 & 0.0000 \\
\hline \multirow[t]{3}{*}{ (SSE) } & Constant, Linear Trend & $\mathrm{D}(\operatorname{SSE}(-1))$ & -4.618973 & 0.218994 & -21.09180 & 0.0000 \\
\hline & None & $\mathrm{D}(\operatorname{SSE}(-1))$ & -4.617405 & 0.218714 & -21.11160 & 0.0000 \\
\hline & Constant & $\mathrm{D}(\mathrm{FTSE}(-1))$ & -11.61910 & 0.862589 & -13.47003 & 0.0000 \\
\hline \multirow[t]{2}{*}{ (FTSE) } & Constant, Linear Trend & $\mathrm{D}(\mathrm{FTSE}(-1))$ & -11.61775 & 0.863150 & -13.45971 & 0.0000 \\
\hline & None & $\mathrm{D}(\operatorname{FTSE}(-1))$ & -11.61870 & 0.862109 & -13.47706 & 0.0000 \\
\hline
\end{tabular}

Table 2: The result of Phillips-Perron (PP) for first order differenced series of S\&P BSE Bankex, S\&P BSE SENSEX, NASDAQ, SSE Composite Index and FTSE 100 market return

\begin{tabular}{|c|c|c|c|c|c|c|}
\hline & Exogenous & Variable & Coefficient & Std. Error & t-Statistic & Prob. \\
\hline & Constant & D(BANKEX(-1)) & -1.415547 & 0.030182 & -46.90103 & 0.0000 \\
\hline \multirow[t]{3}{*}{ (S\&P BSE BANKEX) } & Constant, Linear Trend & D(BANKEX(-1)) & -1.415564 & 0.030198 & -46.87597 & 0.0000 \\
\hline & None & D(BANKEX(-1)) & -1.415547 & 0.030165 & -46.92672 & 0.0000 \\
\hline & Constant & D(SENSEX(-1)) & -1.426699 & 0.030045 & -47.48601 & 0.0000 \\
\hline \multirow[t]{3}{*}{ (S\&P BSE SENSEX) } & Constant, Linear Trend & D(SENSEX(-1)) & -1.426719 & 0.030061 & -47.46063 & 0.0000 \\
\hline & None & D(SENSEX(-1)) & -1.426701 & 0.030028 & -47.51212 & 0.0000 \\
\hline & Constant & D(NASDAQ $(-1))$ & -1.459802 & 0.029484 & -49.51113 & 0.0000 \\
\hline \multirow[t]{3}{*}{ (NASDAQ) } & Constant, Linear Trend & D(NASDAQ $(-1))$ & -1.459820 & 0.029501 & -49.48422 & 0.0000 \\
\hline & None & D(NASDAQ $(-1))$ & -1.459797 & 0.029468 & -49.53813 & 0.0000 \\
\hline & Constant & $\mathrm{D}(\operatorname{SSE}(-1))$ & -1.408604 & 0.030598 & -46.03577 & 0.0000 \\
\hline \multirow[t]{3}{*}{ (SSE) } & Constant, Linear Trend & $\mathrm{D}(\mathrm{SSE}(-1))$ & -1.408610 & 0.030615 & -46.00981 & 0.0000 \\
\hline & None & D(SSE(-1)) & -1.408602 & 0.030581 & -46.06130 & 0.0000 \\
\hline & Constant & D(FTSE $(-1))$ & -1.503965 & 0.028623 & -52.54478 & 0.0000 \\
\hline \multirow[t]{2}{*}{ (FTSE) } & Constant, Linear Trend & D(FTSE $(-1))$ & -1.503964 & 0.028638 & -52.51569 & 0.0000 \\
\hline & None & D(FTSE $(-1))$ & -1.503959 & 0.028607 & -52.57317 & 0.0000 \\
\hline
\end{tabular}

\section{Results and discussion}

Firstly, we have estimated the mean equation, it can be seen from Fig. 1 that there is prolonged period of low volatility from day 1 to day 200 and also there exists a prolonged period of high volatility from day 250 to day 350. In other words, a period of high volatility is followed by a period of high volatility and period of low volatility tend to be followed by periods of low volatility. This suggests that residual or error term is conditionally heteroscedastic and it can be represented by ARCH 
and GARCH Model. In the mean equation, the equation Y (S\&P BSE Bankex return) on X (Sensex Return) Endogenous variable defined the correlation coefficient(r) is 0.85 which is a high degree of positive correlation. The calculated coefficient of determination ( $\mathrm{r} 2$ ) is 0.73 indicating that 73 percent of variance is explained by this relationship. The regression (mean) equation $\mathrm{Y}$ on $\mathrm{X}$ shows that every unit change in $X$ that is SENSEX return there is 1.340233 units change in $\mathrm{Y}$ that is S\&P BSE Bankex return. The Intercept value is 33.68307 indicating the role of other factors (Table 3 ). The $t$ - value is 49.29943 and the p-value is 0.000 , which is less than 0.05 which leads to significant statistically and hence there is the significant relationship between S\&P BSE Bankex and SENSEX return. We plot the residual derived from Eq. 1 as below:
Mean Equation

S\&P BSE Bankex return $=\mathrm{C} 1+\mathrm{C} 2 *$ Sensex return $+\mathrm{e}$

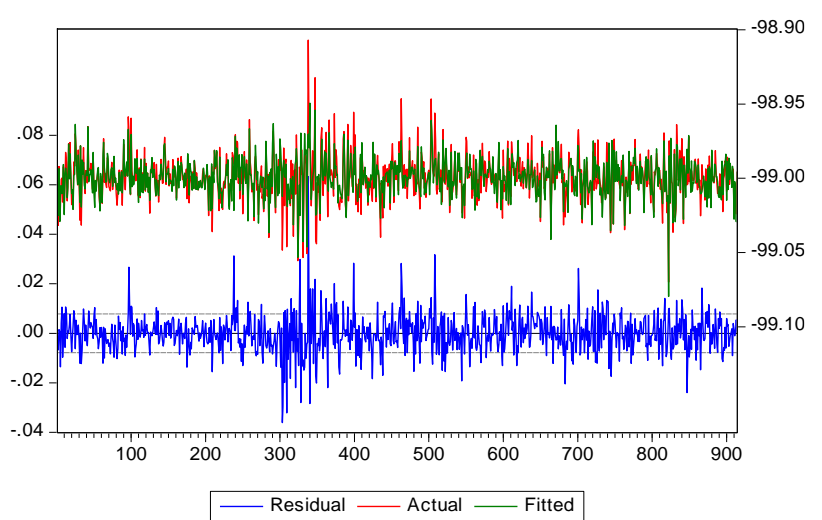

Fig. 1: Actual, fitted and residuals of Bankex return of 914 days

Table 3: Result of residual of Bankex return of 914 days by least squares method

\begin{tabular}{|c|c|c|c|c|}
\hline Variable & Coefficient & Std. Error & t-Statistic & Prob. \\
\hline $\mathrm{C}$ & 33.68307 & 2.691359 & 12.51526 & 0.0000 \\
\hline SENSEX & 1.340233 & 0.027186 & 49.29943 & 0.0000 \\
\hline R-squared & 0.727145 & \multicolumn{2}{|c|}{ Mean dependent var } & -98.99941 \\
\hline Adjusted R-squared & 0.726846 & \multicolumn{2}{|c|}{ S.D. dependent var } & 0.015033 \\
\hline S.E. of regression & 0.007857 & \multicolumn{2}{|c|}{ Akaike info criterion } & -6.852649 \\
\hline Sum squared resid & 0.056299 & \multicolumn{2}{|c|}{ Schwarz criterion } & -6.842107 \\
\hline Log likelihood & 3133.661 & \multicolumn{2}{|c|}{ Hannan-Quinn criterion. } & -6.848625 \\
\hline F-statistic & 2430.435 & \multirow{2}{*}{\multicolumn{2}{|c|}{ Durbin-Watson stat }} & 1.917459 \\
\hline Prob(F-statistic) & 0.000000 & & & \\
\hline
\end{tabular}

After estimated mean equation, we have taken the residual from Eq. 1 and from this residual we have estimated the variances of that residual, so in Eq. 2, estimating GARCH $(1,1)$ Model under the Normal Gaussian distribution.

Variance Equation

$\mathrm{GARCH}=\mathrm{C}(3)+\mathrm{C}(4)^{*} \mathrm{RESID}(-1)^{\wedge} 2+\mathrm{C}(5) * \operatorname{GARCH}(-1)+$ $\mathrm{C}(6) *$ FTSE + C (7) *NASDAQ + C(8)*SSE

Residual derived from mean Eq. 1 is used in making variance Eq. 2 Here,

dependent variable $\mathrm{H}_{\mathrm{t}}=$ variance of the residual (error term) derived from Eq. 1. It is also known as current day's variance or volatility of S\&P BSE Bankex return.

$\mathrm{C}_{3}=$ Constant

$\mathrm{H}_{\mathrm{t}-1}=$ previous day's residual variance or volatility of S\&P BSE Bankex return. It is known Garch term or (volatility of S\&P BSE Bankex return)

$\mathrm{e}_{\mathrm{t}-1}=$ previous period squared residual derived from Eq. 1. It is also known as previous day's S\&P BSE Bankex return information about volatility. It is Arch term.

NASDAQ, SSE Composite Index and FTSE 100 are exogenous or predetermined variables, are also known as regressors as they can also contribute to the volatility of S\&P BSE BANKEX return $\left(\mathrm{H}_{\mathrm{t}}\right)$ in Eq. 2.

In Eq. 2 is a GARCH $(1,1)$ model as it has one Arch $\left(\mathrm{e}^{2} \mathrm{t}-1\right)$ and one GARCH term $\left(\mathrm{H}_{\mathrm{t}-1}\right)$. The variance of residual shows $\left(\mathrm{H}_{\mathrm{t}}\right) \mathrm{GARCH}$, and it has become dependent variable (volatility of S\&P Bankex return) or variance of residual, the equation shows that arch term resid ( -1$) \wedge_{2}$ and GARCH term (GARCH-1) are statistically significant with p-value (0.003) and (0.000) which is less than 0.05, which leads to the conclusion that ARCH AND GARCH are own shock or internal shock of S\&P Bankex return volatility. An exogenous variables NASDAQ, SSE composite index return are also significant, the p- value of NASDAQ and SSE return are (0.0000) and (0.0000). However FTSE 100 returns shows the p-value $(0.3405)$ which is more than 0.05 and leads to insignificant statistically (Table 4).So it concluded that volatility in S\&P BSE BANKEX return is largely dependent on its own shocks, such as ARCH and GARCH and also influenced by the foreign market such as NASDAQ, and SSE, but the volatility of FTSE return cannot contribute to the volatility of S\&P BSE BANKEX return. The results of hypotheses testing exhibit that all three null hypotheses are rejected.

The GARCH $(1,1)$ model is viable or not, the researcher test all the conventions for forecasting the S\&P BSE Bankex return volatility by testing serial correlation, ARCH effect and normally distribution of residuals and Squares of residuals. Firstly, Autocorrelation: This is a test to check whether the model is viable or acceptable that there is no serial correlation in the residual term or error term using correlogram square residual (Q-test can be performed). And shows that all the p-value of Qstatistics of 34 lags are more than 0.05 , leads to the acceptance of Null hypothesis, that mention that there is no serial correlation in the residual or error term (Table 5).

Secondly, ARCH effect: It can be tested in pre and post estimation analysis, in post estimation, its test 
remaining ARCH effect i.e., whether or not conditional Heteroscedasticity has been removed. For this purpose, it applied standardized residual. The guidelines of the LM - test, the null hypothesis assumes that there is no ARCH effect. In Table 6, the result shows f-statistic 0.379026 with p-value 0.5383 which is more than 0.05 , it leads to insignificant statisticallyand the Null Hypothesis of
LM-test is accepted. The result clearly stated that the Garch 1, 1 model does not have any arch effect. Thirdly, Jarque-Bera test statistics: Normality test is used to test the behavior of residual, the Jarque-Bera statistics show that the p-value 0.392278 which is more than 0.05 , indicates that the residual are normally distributed (Fig. 2).

Table 4: Result of GARCH $(1,1)$ model using ML-ARCH (Marquardt) normal distribution method

\begin{tabular}{|c|c|c|c|c|}
\hline \multicolumn{5}{|c|}{ Mean Equation } \\
\hline Variable & Coefficient & Std. Error & z-Statistic & Prob. \\
\hline C & 33.68203 & 2.162573 & 15.57498 & 0.0000 \\
\hline SENSEX & 1.340222 & 0.021844 & 61.35338 & 0.0000 \\
\hline \multicolumn{5}{|c|}{ Variance Equation } \\
\hline $\mathrm{C}$ & 0.000671 & $4.12 \mathrm{E}-05$ & 16.30412 & 0.0000 \\
\hline $\operatorname{RESID}(-1)^{\wedge} 2$ & 0.103274 & 0.028379 & 3.639064 & 0.0003 \\
\hline GARCH(-1) & 0.718117 & 0.033089 & 21.70288 & 0.0000 \\
\hline FTSE & $-4.24 \mathrm{E}-06$ & $4.45 \mathrm{E}-06$ & -0.953241 & 0.3405 \\
\hline NASDAQ & $1.84 \mathrm{E}-05$ & $4.45 \mathrm{E}-06$ & 4.141971 & 0.0000 \\
\hline SSE & $-7.49 \mathrm{E}-06$ & $4.23 \mathrm{E}-07$ & -17.71476 & 0.0000 \\
\hline R-squared & 0.727136 & \multicolumn{2}{|c|}{ Mean dependent var } & -98.99941 \\
\hline Adjusted R-squared & 0.726837 & \multicolumn{2}{|c|}{ S.D. dependent var } & 0.015033 \\
\hline S.E. of regression & 0.007857 & \multicolumn{2}{|c|}{ Akaike info criterion } & -6.918047 \\
\hline Sum squared resid & 0.056301 & \multicolumn{2}{|c|}{ Schwarz criterion } & -6.875878 \\
\hline Log likelihood & 3169.548 & \multicolumn{2}{|c|}{ Hannan-Quinn criter. } & -6.901950 \\
\hline Durbin-Watson stat & 1.917394 & & & \\
\hline
\end{tabular}

Table 5: Autocorrelation and partial autocorrelation function of correlogram of Standardized Residuals Squared

\begin{tabular}{|c|c|c|c|c|c|c|}
\hline Autocorrelation & Partial Correlation & & $\mathrm{AC}$ & PAC & Q-Stat & Prob. \\
\hline $\begin{array}{ll}. & 1\end{array}$ & $\begin{array}{ll} & 1\end{array}$ & 1 & -0.020 & -0.020 & 0.3813 & 0.537 \\
\hline. $\mid$ & .1 & 2 & 0.004 & 0.003 & 0.3935 & 0.821 \\
\hline .1 & .1 & 3 & 0.008 & 0.008 & 0.4453 & 0.931 \\
\hline .1 & .1 & 4 & -0.042 & -0.042 & 2.0977 & 0.718 \\
\hline .1 & .1 & 5 & 0.002 & 0.000 & 2.1022 & 0.835 \\
\hline. & .1 & 6 & 0.042 & 0.042 & 3.7180 & 0.715 \\
\hline .1 & .1 & 7 & 0.001 & 0.003 & 3.7192 & 0.811 \\
\hline .1 &. $\mid$ & 8 & -0.007 & -0.009 & 3.7645 & 0.878 \\
\hline .1 & .1 & 9 & 0.008 & 0.007 & 3.8211 & 0.923 \\
\hline .1 & .1 & 10 & 0.031 & 0.035 & 4.7218 & 0.909 \\
\hline $.1^{*} \quad \mid$ & $.1^{*} \quad \mid$ & 11 & 0.100 & 0.102 & 14.019 & 0.232 \\
\hline .1 & .1 & 12 & 0.007 & 0.009 & 14.066 & 0.297 \\
\hline .1 & .1 & 13 & -0.000 & -0.001 & 14.066 & 0.369 \\
\hline .1 & .1 & 14 & -0.009 & -0.007 & 14.136 & 0.440 \\
\hline .1 & .1 & 15 & -0.013 & -0.006 & 14.299 & 0.503 \\
\hline .1 & .1 & 16 & -0.023 & -0.026 & 14.808 & 0.539 \\
\hline $.1^{*} \quad \mid$ & .1 & 17 & 0.076 & 0.068 & 20.258 & 0.261 \\
\hline .1 & .1 & 18 & 0.034 & 0.037 & 21.353 & 0.262 \\
\hline .1 & .1 & 19 & 0.009 & 0.011 & 21.435 & 0.313 \\
\hline.$j$ & .1 & 20 & 0.025 & 0.020 & 22.011 & 0.340 \\
\hline .1 & .1 & 21 & -0.024 & -0.024 & 22.550 & 0.368 \\
\hline .1 & .1 & 22 & -0.017 & -0.025 & 22.822 & 0.412 \\
\hline .1 & .1 & 23 & 0.001 & -0.007 & 22.822 & 0.471 \\
\hline .1 & .1 & 24 & 0.065 & 0.066 & 26.759 & 0.316 \\
\hline .1 & .1 & 25 & 0.015 & 0.020 & 26.969 & 0.357 \\
\hline $.1^{*} \quad \mid$ & $.1^{*} \quad \mid$ & 26 & 0.091 & 0.094 & 34.742 & 0.117 \\
\hline .1 & .1 & 27 & -0.019 & -0.014 & 35.067 & 0.137 \\
\hline .1 &.$j$ & 28 & 0.006 & -0.005 & 35.104 & 0.167 \\
\hline .1 & .1 & 29 & 0.068 & 0.060 & 39.534 & 0.092 \\
\hline .1 & .1 & 30 & -0.020 & -0.019 & 39.904 & 0.107 \\
\hline .1 & .1 & 31 & -0.016 & -0.023 & 40.160 & 0.125 \\
\hline .1 & .1 & 32 & 0.015 & 0.016 & 40.366 & 0.147 \\
\hline .1 & .1 & 33 & -0.018 & -0.001 & 40.659 & 0.169 \\
\hline .1 & .1 & 34 & 0.016 & 0.009 & 40.906 & 0.193 \\
\hline
\end{tabular}

\section{Conclusion}

Using GARCH $(1,1)$ model to check volatility of S \& P Bankex return and the factors affecting the return of S\&P BSE Bankex return in India. The researcher estimated mean and variance equation under the study. This model used generated by using Eq. 1, residual have been examined by using correlogram of squared residual, Q-statistics at different lags and the application of LM-test and JarquaBera test for normally distributed residual gave the best-suited model under Normal distribution method. The results show that there is no serial correlation in residual or error term, no $\mathrm{ARCH}$ effect and the residual are normally distributed. 
In the mean equation, z-statistics of SENSEX return is significantly impact on the volatility of Bankex return in residual term, the variance equation has shown the ARCH is significant in the residual term and showed not any arch effect in the residual by using normal distribution model, this shows goodness of fit Garch $(1,1)$ model has better ability of capturing of volatility among all estimated
Arch models in case of S\&P BSE Bankex return. The results indicate that S\&P BSE Bankex return volatility not only shows ARCH AND GARCH effect but also shows significant influenced by National market (SENSEX) return volatility and also influence or transmit outside shock in the International market return namely the Nasdaq and Shanghai stock Exchange.

Table 6: Result of heteroskedasticity test (ARCH) by least squares method

\begin{tabular}{|c|c|c|c|c|}
\hline F-statistic & 0.379026 & \multicolumn{2}{|c|}{ Prob. F(1,911) } & 0.5383 \\
\hline Obs*R-squared & 0.379701 & \multicolumn{2}{|c|}{ Prob. Chi-Square(1) } & 0.5378 \\
\hline Variable & Coefficient & Std. Error & t-Statistic & Prob. \\
\hline $\mathrm{C}$ & 1.083399 & 0.101553 & 10.66835 & 0.0000 \\
\hline WGT_RESID^2(-1) & -0.020395 & 0.033127 & -0.615651 & 0.5383 \\
\hline R-squared & 0.000416 & \multicolumn{2}{|c|}{ Mean dependent var } & 1.061729 \\
\hline Adjusted R-squared & -0.000681 & \multicolumn{2}{|c|}{ S.D. dependent var } & 2.877308 \\
\hline S.E. of regression & 2.878288 & \multicolumn{2}{|c|}{ Akaike info criterion } & 4.954457 \\
\hline Sum squared resid & 7547.217 & \multicolumn{2}{|c|}{ Schwarz criterion } & 4.965008 \\
\hline Log likelihood & -2259.709 & \multicolumn{2}{|c|}{ Hannan-Quinn criter. } & 4.958485 \\
\hline F-statistic & 0.379026 & \multicolumn{2}{|c|}{ Durbin-Watson stat } & 1.999722 \\
\hline Prob(F-statistic) & 0.538279 & & & \\
\hline
\end{tabular}

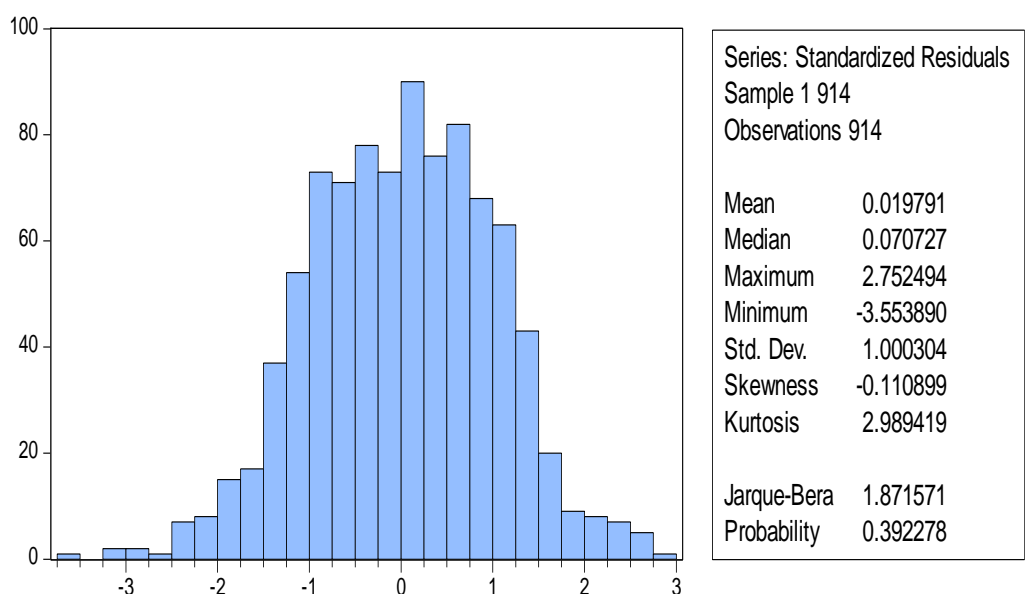

Fig. 2: Results of normality (Jarque-Bera) test of GARCH model

\section{References}

Aggarwal R, Inclan C, and Leal R (1999). Volatility in emerging stock markets. Journal of Financial and Quantitative Analysis, 34(01): 33-55.

Alberg D, Shalit H, and Yosef R (2008). Estimating stock market volatility using asymmetric GARCH models. Applied Financial Economics, 18(15): 1201-1208.

Birău R, Trivedi J, and Antonescu M (2015). Modeling S \& P Bombay stock exchange BANKEX index volatility patterns using GARCH model. Procedia Economics and Finance, 32: 520-525.

Bollerslev $\mathrm{T}$ (1986). Generalized autoregressive conditional heteroskedasticity. Journal of Econometrics, 31(3): 307-327.

Chand S, Kamal S, and Ali I (2012). Modelling and volatility analysis of share prices using ARCH and GARCH models. World Applied Sciences Journal, 19(1): 77-82.

Engle RF (1982). Autoregressive conditional heteroscedasticity with estimates of the variance of United Kingdom inflation. Econometrica: Journal of the Econometric Society, 50(4): $987-$ 1007.

Engle RF and Ng VK (1993). Measuring and testing the impact of news on volatility. The Journal of Finance, 48(5): 1749-1778.

French KR, Schwert GW, and Stambaugh RF (1987). Expected stock returns and volatility. Journal of Financial Economics, 19(1): 3-29.
Goudarzi H and Ramanarayanan CS (2011). Modeling asymmetric volatility in the Indian stock market. International Journal of Business and Management, 6(3): 221-231.

Joshi P (2010). Modeling volatility in emerging stock markets of India and China. Journal of Quantitative Economics, 8(1): 8694.

Karmakar M (2005). Modeling conditional volatility of the Indian stock markets. Vikalpa, 30(3): 21-38.

Kaur H (2004). Time varying volatility in the Indian stock market. Vikalpa, 29(4): 25-42.

Kulkarni V and Deo N (2005). Correlation and volatility in an Indian stock market: A random matrix approach. The European Physical Journal B, 60(1): 101 -109.

Mandelbrot B (1963). The variation of certain speculative prices. The Journal of Business, 36(4): 394-419.

Pandey A (2005). Volatility models and their performance in Indian capital markets. Vikalpa, 30(2): 27-46.

Prasanna PK and Menon AS (2013). Speed of information adjustment in Indian stock indices. IIMB Management Review, 25(3): 150-159.

Schwert GW (1989). Why does stock market volatility change over time?. The Journal of Finance, 44(5): 1115-1153.

Trivedi JC (2013). Performance analysis of BANKEX banks through camel model. Management Dynamics, 13(2): 1-13. 